\title{
Using the Maximum Entropy Production approach to integrate energy budget modeling in a hydrological model
}

\author{
Audrey Maheu ${ }^{1}$, Islem Hajji ${ }^{2}$, François Anctil ${ }^{2}$, Daniel F. Nadeau ${ }^{2}$, René Therrien ${ }^{3}$ \\ ${ }^{1}$ Département des sciences naturelles, Université du Québec en Outaouais, Ripon, J0V 1V0, Canada \\ ${ }^{2}$ Département de génie civil et de génie des eaux, Université Laval \\ ${ }^{3}$ Département de géologie et de génie géologique, Université Laval \\ Correspondence to: Audrey Maheu (audrey.maheu@uqo.ca)
}

\section{Contents of this file}

Figures $\mathrm{S} 1$ to $\mathrm{S} 3$

Table S1

\section{Introduction}

Figures S1 to S3 supplement the manuscript by providing time series of observed and modelled soil moisture at multiple depths, rather than a single one, as presented in the manuscript. There is one figure per study site (S1: US-Wkg, S2: USTon and S3: US-WBW).

Table S1 provides the equation of performance metrics (RMSE, NSE, BE, R², PBIAS) using to compare simulated and observed values. 

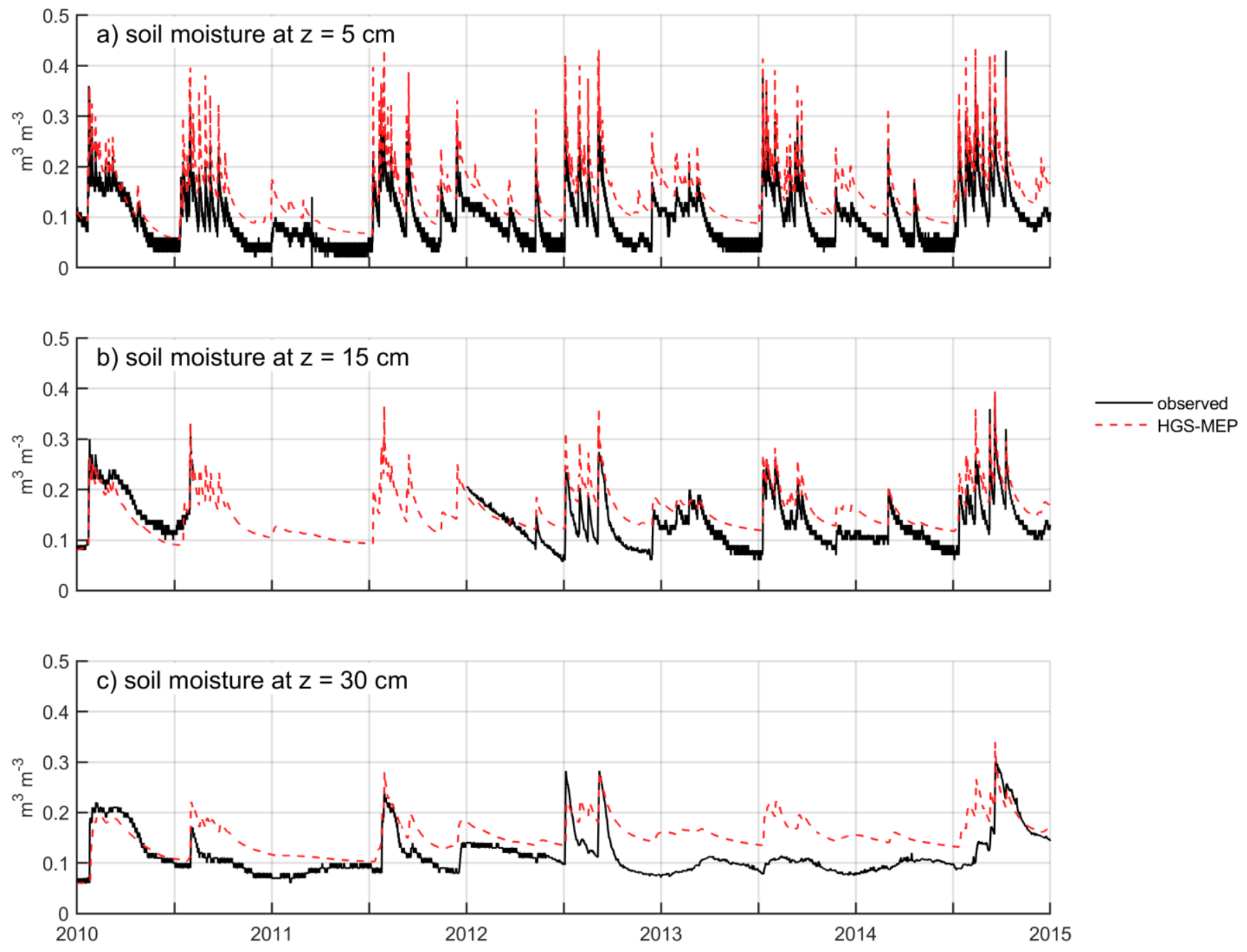

Figure S1. Time series of observed and modelled soil moisture at a depth of a) $5 \mathrm{~cm}$, b) $15 \mathrm{~cm}$ and c) $30 \mathrm{~cm}$ at US-Wkg (climate: semiarid, vegetation: grassland). 

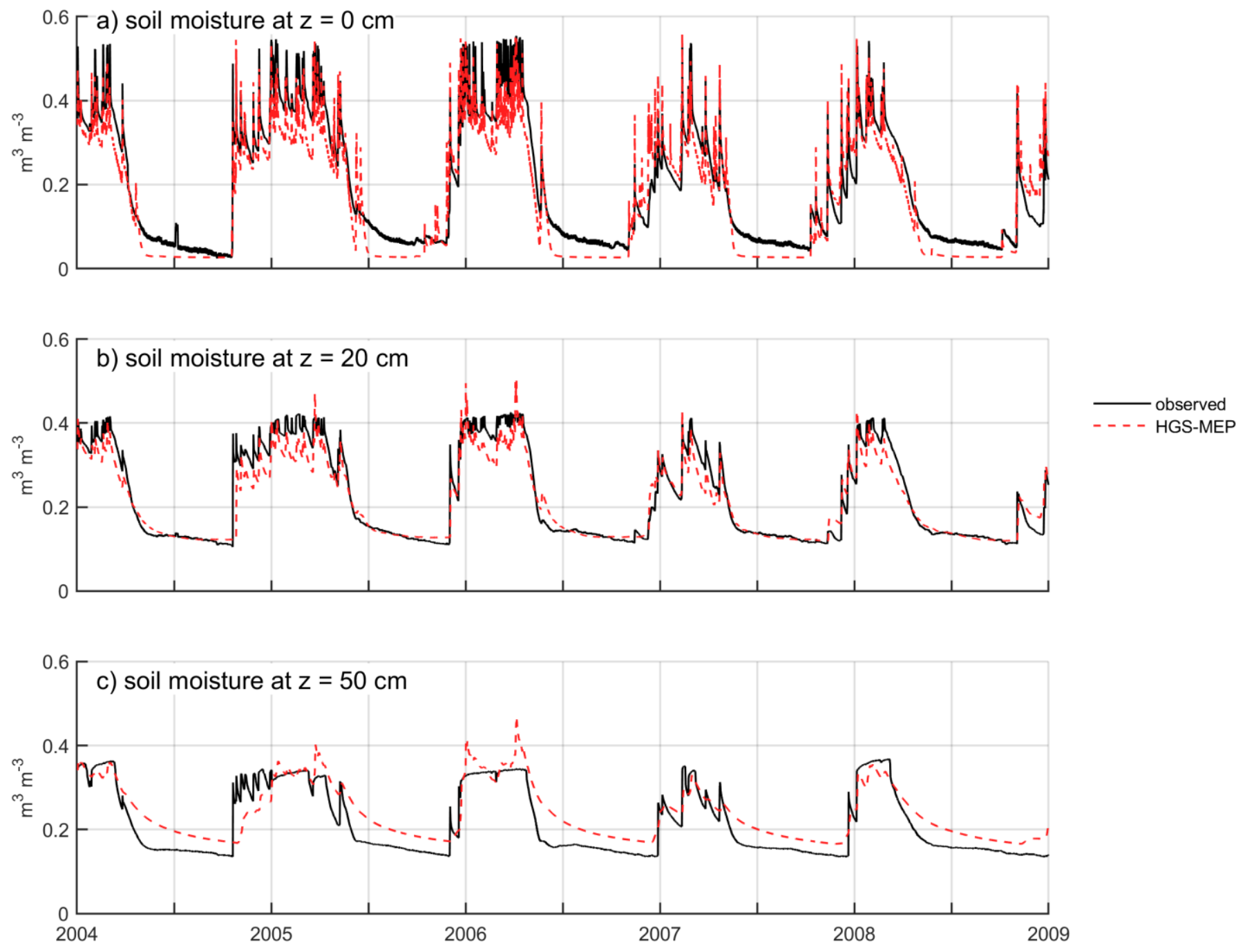

Figure S2. Time series of observed and modelled soil moisture at a depth of a) $0 \mathrm{~cm}$, b) $20 \mathrm{~cm}$ and c) $50 \mathrm{~cm}$ at US-Ton (climate: Mediterranean, vegetation: woody savanna). 

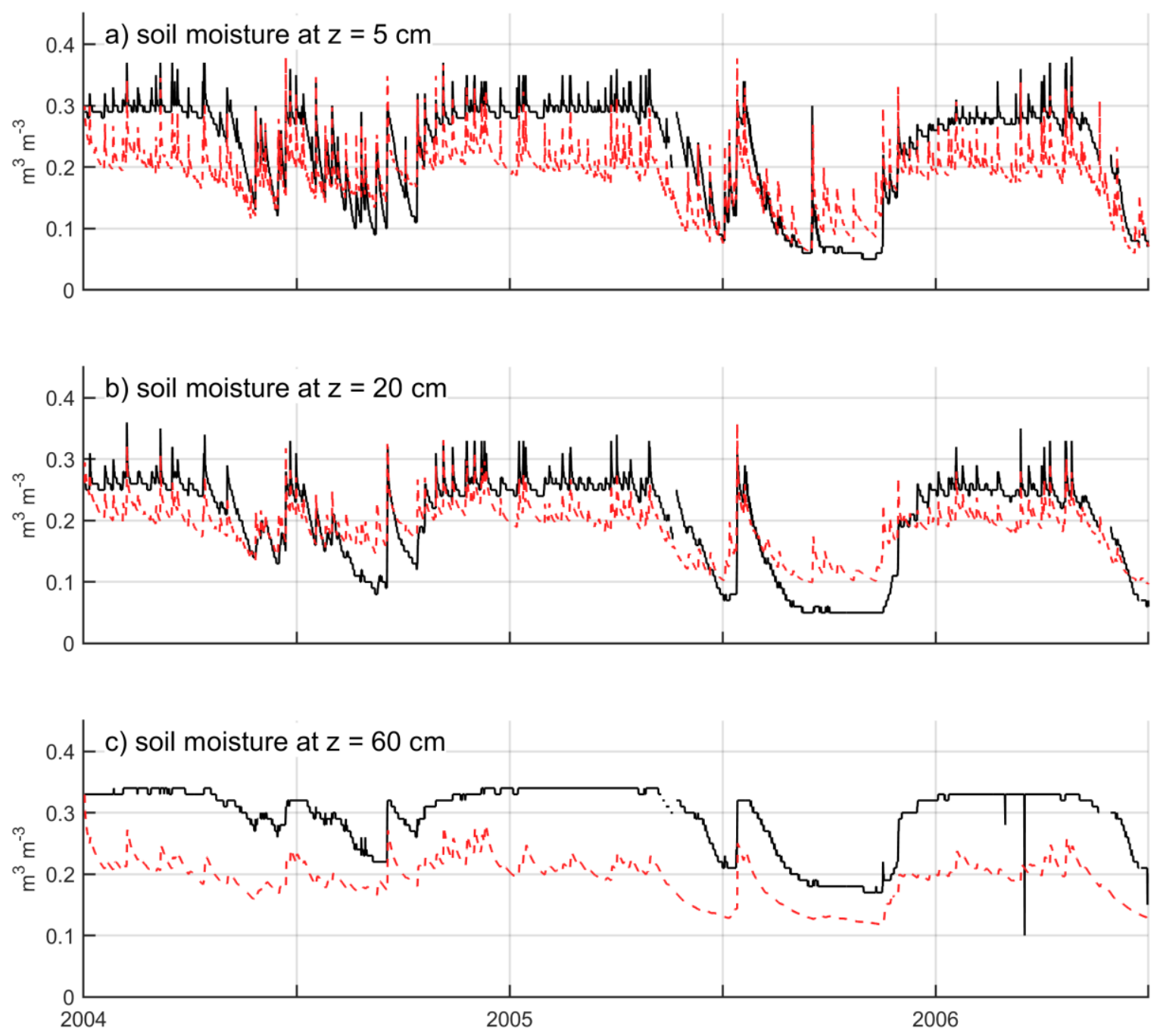

Figure S3. Time series of observed and modelled soil moisture at a depth of a) $5 \mathrm{~cm}$, b) $20 \mathrm{~cm}$ and c) $60 \mathrm{~cm}$ at US-WBW (climate: temperate, vegetation: deciduous broadleaf forest). 
Table S1. Equation of performance metrics to compare observed and simulated values.

\begin{tabular}{|c|c|}
\hline metric & equation \\
\hline root mean square error & $\mathrm{RMSE}=\sqrt{\frac{1}{N} \sum_{t=1}^{N}\left[x_{\text {sim }}(t)-x_{\text {obs }}(t)\right]^{2}}$ \\
\hline Nash-Sutcliffe efficiency (NSE) & $\mathrm{NSE}=1-\left[\frac{\underset{t=1}{N}\left[x_{\text {sim }}(t)-x_{o b s}(t)\right]^{2}}{\underset{t=1}{N}\left[x_{o b s}(t)-x_{o b s}\right]^{2}}\right]$ \\
\hline normalized benchmark efficiency (BE) & $\mathrm{BE}=1-\left[\frac{\underset{t=1}{N}\left[x_{\text {sim }}(t)-x_{\text {obs }}(t)\right]^{2}}{\underset{t=1}{N}\left[x_{\text {obs }}(t)-x_{\text {bench }}(t)\right]^{2}}\right]$ \\
\hline coefficient of determination $\left(\mathrm{R}^{2}\right)$ & $R^{2}=\frac{\frac{1}{N}{ }_{t=1}^{N}\left[\left(x_{o b s}(t)-x_{o b s}\right)\left(x_{s i m}(t)-x_{o b s}\right)\right]}{\frac{N{ }_{t=1}^{N} x_{o b s}^{2}-\left[\begin{array}{c}N \\
N(N-1)\end{array} x_{o b s}(t)\right]^{2}}{\frac{N{ }_{t=1}^{N} x_{\text {sim }}^{2}-\left[\begin{array}{c}N \\
N(N-1)\end{array} x_{s i m}(t)\right]^{2}}{N(N-1)}}}$ \\
\hline percent bias (PBIAS) & PBIAS $=\frac{\underset{t=1}{N}\left[x_{\text {sim }}(t)-x_{o b s}(t)\right]}{\underset{t=1}{N}\left[x_{o b s}(t)\right]} * 100$ \\
\hline
\end{tabular}

where $x_{o b s}(t)$ is the observed value at time step $t, x_{o b s}(t)$ is the simulated value, $\bar{x}_{o b s}$ is the mean observed value over the simulation period of length $N, x_{\text {bench }}$ is the benchmark model, in this case the interannual mean of observed values for each calendar day. 